\title{
ANALISIS EFISIENSI BANK PERKREDITAN RAKYAT DI KOTA SEMARANG DENGAN PENDEKATAN DATA ENVOLEPMENT ANALYSIS
}

\author{
Hendi Septianto ${ }^{1}$, Tatik Widiharih ${ }^{2}$ \\ ${ }^{1}$ Alumni Program Studi Statistika FMIPA UNDIP \\ ${ }^{2}$ Staf Pengajar Program Studi Statistika FMIPA UNDIP
}

\begin{abstract}
The research was conducted to measure rural banks (Bank Perkreditan Rakyat / BPR) efficiency level in Semarang city. The measurement was done using non parametric approach with Data Envolepment Analysis (DEA) method constant return to scale assumption (CCR model). The research was using all rural banks in Semarang (16 rural banks). The result indicated that 6 rural banks were efficient and 10 rurals banks were inefficient.
\end{abstract}

Keywords: CCR Model, Efficient, Rural Bank

\section{Pendahuluan}

Sektor keuangan, terutama industri perbankan, berperan sangat penting bagi aktivitas perekonomian. Bank merupakan lembaga keuangan terpenting dan sangat mempengaruhi perekonomian suatu bangsa baik secara mikro maupun makro. Peran strategis bank tersebut sebagai wahana yang mampu menghimpun dan menyalurkan dana masyarakat secara efektif dan efisien kearah peningkatan taraf hidup rakyat. Di Indonesia, perbankan mempunyai pangsa pasar sebesar 80 persen dari keseluruhan sistem keuangan yang ada ${ }^{[1]}$.

Lembaga keuangan yang tepat dan strategis untuk melayani jasa perbankan bagi masyarakat adalah Bank Perkreditan Rakyat (BPR). Bank Perkreditan Rakyat (BPR) dituntut untuk dapat bertahan menghadapi krisis ekonomi global yang terjadi saat ini karena BPR berperan penting dalam memberikan pembiayaan pada sektor UMKM (Usaha Mikro, Kecil dan Menengah) di seluruh daerah. BPR memiliki prosedur pelayanan yang sederhana, proses yang cepat dan skema kredit yang lebih mudah disesuaikan serta lokasi tersebar di seluruh daerah baik perkotaan maupun pedesaan dibandingkan dengan bank umum. Bank umum juga berperan dalam memberikan pembiayaan tetapi dengan bentuk kredit yang baku (tidak dapat disesuaikan) serta lokasinya yang hanya ada di perkotaan. Mengingat begitu besarnya peranan Bank Perkreditan Rakyat (BPR), para pengambil keputusan (manajer) perlu melakukan evaluasi kinerja bank yang memadai.

Untuk mengukur kinerja bank diperlukan suatu teknik perhitungan yang dapat mengetahui seluruh produktifitas suatu bank. Teknik tersebut disebut juga sebagai metode analisis efisiensi. Dalam hal ini efisiensi yang dimaksud adalah efisiensi relative. Efisiensi relative suatu BPR adalah efisiensi BPR dibandingkan dengan BPR lain dalam sampel yang menggunakan jenis input dan output yang sama. Sedangkan nilai efisiensi relative merupakan rasio total output tertimbang dengan total input tertimbang. Metode analisis efisiensi terbagi menjadi dua pendekatan yaitu pendekatan parametrik dan pendekatan non parametrik. Pendekatan parametrik diantaranya Stochastic Frontier Approach dan Distribution Free Approach. Pendekatan non parametrik diantaranya Data Envelopment Analysis dan Free Disposable Hull ${ }^{[4],[2]}$. Dengan metode analisis efisiensi maka dapat mengetahui bank-bank mana yang telah efisien dalam hal penggunaan input dan 
pengeluaran output. Metode analisis efisiensi yang paling banyak dipakai adalah metode Data Envelopment Analysis (DEA) karena pendekatan DEA tidak membutuhkan banyak informasi sehingga lebih sedikit data yang dibutuhkan dan lebih sedikit asumsi yang diperlukan.

Dalam penelitian ini akan dihitung efisiensi pada setiap BPR yang ada dikota Semarang (16 BPR). Untuk BPR yang belum efisien diberikan masukan untuk mengoptimalkan efisiensi dengan cara mencapai target sesuai perhitungan dengan pembanding BPR yang telah efisien.

\section{Tinjauan Pustaka}

\subsection{Bank Perkreditan Rakyat}

Bank Perkreditan Rakyat (BPR) menurut Undang-Undang No.10 Tahun 1998 atas perubahan UU No. 7 Tahun 1992 tentang perbankan, adalah bank yang melaksanakan kegiatan usaha secara konvensional atau berdasarkan prinsip syariah yang kegiatannya tidak memberikan jasa dalam lalu lintas pembayaran. BPR terdiri dari BPR non BKD (Badan Kredit Desa), BPR BKD, dan LDKP (Lembaga Dana Kredit Pedesaan). BPR non BKD adalah BPR yang baru didirikan setelah adanya kebijakan Pakto 1988 dan Bank Pasar/ Bank Desa. BPR BKD terdiri dari Bank Desa dan Lumbung Desa yang hanya terdapat di daerah Jawa dan Madura, yang didirikan sejak masa Belanda. Sedangkan LDKP terdiri dari Lumbuh Pilih Nagari, Badan Kredit Kecamatan, Lembaga Kredit Usaha Rakyat Kecil, Lembaga Pekreditan Kecamatan, dan Lembaga Perkreditan Pedesaan.

Fungsi BPR secara umum adalah sebagai badan usaha yang menghimpun dan menyalurkan dana masyarakat, harus mampu menunjang modernisasi pedesaan dan memberikan layanan jasa perbankan bagi golongan ekonomi lemah /pengusaha kecil seperti tercantum pada Undang-Undang No.10 Tahun 1998 tentang perbankan. Pelayanan BPR sebagian besar diberikan kepada masyarakat yang bermodal kecil, yang sebagian besar berada dalam sektor informal. Oleh karena itu perbaikan kinerja baik manajemen, administrasi harus ditingkatkan kualitasnya. Disamping menyangkut perkembangan BPR itu sendiri juga menyangkut perkembangan sektor riil yang tumbuh dari sektor informal yang merupakan bagian terbesar dari perekonomian masyarakat. Di Kota Semarang ada sebanyak 16 BPR.

\subsection{Data Envolepment Analysis (DEA)}

DEA merupakan prosedur yang dirancang secara khusus untuk mengukur efisiensi relatif suatu unit organisasi yang disebut sebagai DMU (Decision Making Unit) yang menggunakan beberapa variabel input dan output, dimana penggabungan input dan output tersebut tidak mungkin dilakukan. Efisiensi relatif suatu DMU adalah efisiensi suatu DMU dibanding dengan DMU lain dalam sampel (sekelompok DMU yang saling diperbandingkan) yang menggunakan jenis input dan output yang sama ${ }^{[3],[5]}$.

Model DEA digunakan sebagai perangkat untuk mengukur kinerja efisien setidaknya memiliki 3 keunggulan dibandingkan model lain misalnya model regresi linear berganda. Keunggulan tersebut antara lain:

1. Model DEA dapat mengukur beberapa variabel input dan variabel output.

2. Tidak diperlukan asumsi hubungan fungsional antara variabel-variabel yang diukur.

3. Variabel input dan output dapat memiliki satuan pengukuran yang berbeda.

Dalam DEA, efisiensi relatif suatu DMU didefinisikan sebagai rasio dari total output terbobot dibagi total input terbobot (total weighted output/total weighted input) ${ }^{[3]}$ yaitu: 


$$
\text { Efisiensi Relatif }=\frac{\text { Total output tebobot }}{\text { Totalinput terbobot }}=\frac{\text { Virtual output }}{\text { Virtual input }}
$$

Nilai efisiensi relatif berkisar antara 0 sampai dengan 1 atau 0 sampai $100 \%$. Suatu DMU memiliki kemampuan paling baik jika nilai efisiensi relatif sebesar 1 atau $100 \%$ sedangkan DMU lain yang nilainya dibawah $100 \%$ maka kemampuannya masih dibawah DMU yang telah efisien.

DMU dikatakan efisien jika:

1. Dari segi orientasi output

Efisiensi naik jika:

a. Output naik saat input tetap

b. Output tetap saat input turun

2. Dari segi orientasi input

Efisiensi naik jika:

a. Input tetap saat output naik

b. Input turun saat output tetap

Inti dari DEA adalah menentukan bobot (weights) untuk setiap input dan output suatu DMU. Dari rumusaan Efisiensi Relatif tersebut, diperoleh bentuk matematis program nonlinier. Untuk menyelesaikanya dibawa kebentuk program liniar. DEA memberi kebebasan pada setiap DMU untuk menentukan pembobotnya masing-masing. Bobot tersebut memiliki sifat:

- Bobot tidak boleh bernilai negatif.

- Bobot harus bersifat universal atau tidak menghasilkan indikator efisiensi di atas normal atau lebih besar dari nilai satu.

Setiap DMU akan memilih bobot yang akan memaksimalkan rasio efisiensinya (total weighted output/total weighted input).

DEA juga berfungsi sebagai alat benchmarking ${ }^{[6]}$. Pertama, karena DEA menghasilkan efisiensi untuk setiap DMU, relatif terhadap DMU yang lain didalam sampel. Angka efisiensi ini memungkinkan seorang analisis untuk mengenali DMU yang paling membutuhkan perhatian dan merencanakan tindakan perbaikan bagi DMU yang tidak/kurang efisien. Kedua, jika suatu DMU kurang efisien (nilai efisiensi < 100\%), DEA menunjukkan sejumlah DMU yang memiliki efisiensi sempurna (efficient reference set, nilai efisiensi $=100 \%$ ) dan seperangkat angka pengganda (multipliers) yang dapat digunakan oleh manajer untuk menyusun strategi perbaikan. Informasi tersebut memungkinkan seorang analisis membuat DMU hipotesis yang menggunakan input yang lebih sedikit dan menghasilkan output yang paling tidak sama atau lebih banyak dibanding DMU yang tidak efisien, sehingga DMU hipotesis tersebut akan memiliki efisiensi yang sempurna jika menggunakan bobot input dan bobot output dari DMU yang tidak efisien.

Ada dua macam model didalam metode Data Envelopment Analysis (DEA).

Model yang pertama kali diperkenalkan adalah model DEA Constant Return To Scale (CRS) atau dilihat dari nama penemunya disebut juga sebagai model Charnes, Cooper dan Rhodes (CCR) dan model yang kedua adalah model DEA Variabel Returns To Scale (VRS) atau yang biasa disebut juga model Barnes, Charnes dan Cooper (BCC) sesuai dengan nama penemunya ${ }^{[3]}$. Pada penelitian ini digunakan metode DEA Constant Return To Scale (CRS). 


\subsubsection{Model Data Envelopment Analysis Constant Return To Scale}

Model Data Envelopment Analysis Constant Return To Scale ditemukan oleh Charnes, Cooper dan Rhodes pada tahun 1978. Pada model ini diperkenalkan suatu ukuran efisiensi untuk masing-masing decision making unit (DMU) yang merupakan rasio maksimum antara output yang terbobot dengan input yang terbobot ${ }^{[3]}$.

Misalkan dipunyai $\mathrm{n}$ buah DMU yaitu $\mathrm{DMU}_{1}, \mathrm{DMU}_{2}, \ldots, \mathrm{DMU}_{\mathrm{n}}$, dengan $m$ buah variabel input dan $s$ buah variabel output. Pada masing-masing unit DMU mempunyai input dan output berbentuk vektor baris sebagai berikut:

Untuk $\mathrm{DMU}_{\mathrm{i}}$ mempunyai vektor input $\mathrm{DMU}_{\mathrm{i}}=\left(\mathrm{x}_{\mathrm{i} 1}, \mathrm{x}_{\mathrm{i} 2}, \ldots, \mathrm{x}_{\mathrm{im}}\right)$ dan vektor output $\mathrm{DMU}_{\mathrm{i}}=\left(\mathrm{y}_{\mathrm{i} 1}, \mathrm{y}_{\mathrm{i} 2}, \ldots, \mathrm{y}_{\mathrm{is}}\right)$, dengan $\mathrm{x}_{\mathrm{ij}}$ adalah nilai input pada DMU $\mathrm{U}_{\mathrm{i}}$ input ke-j dan $\mathrm{y}_{\mathrm{ij}}$ adalah nilai output pada $\mathrm{DMU}_{\mathrm{i}}$ output ke-j. Sedangkan $\mathbf{X}$ adalah matriks data kumpulan seluruh input dari seluruh DMU yang berdimensi $n \times m$ dan $\mathbf{Y}$ adalah matriks data kumpulan seluruh output dari seluruh DMU yang berdimensi $n \times s$.

$$
X_{n m}=\left[\begin{array}{cccc}
x_{11} & x_{12} & \ldots & x_{1 m} \\
x_{21} & x_{22} & & x_{2 m} \\
\vdots & & \ddots & \vdots \\
x_{n 1} & x_{n 2} & \ldots & x_{n m}
\end{array}\right] \quad Y_{n s}=\left[\begin{array}{cccc}
y_{11} & y_{12} & \ldots & y_{1 s} \\
y_{21} & y_{22} & & y_{2 s} \\
\vdots & & \ddots & \vdots \\
y_{n 1} & y_{n 2} & \ldots & y_{n s}
\end{array}\right]
$$

Dari masing-masing DMU pada matrik $\mathrm{X}$ dan $\mathrm{Y}$ di atas diberikan bobot yang tidak diketahui nilainya untuk setiap nilai input dan nilai outputnya, yaitu :

$$
X_{n m}^{*}=\left[\begin{array}{cccc}
v_{11} x_{11} & v_{12} x_{12} & \ldots & v_{1 m} x_{1 m} \\
v_{21} x_{21} & v_{22} x_{22} & & v_{2 m} x_{2 m} \\
\vdots & & \ddots & \vdots \\
v_{n 1} x_{n 1} & v_{n 2} x_{n 2} & \ldots & v_{n m} x_{n m}
\end{array}\right] \quad Y_{n s}^{*}=\left[\begin{array}{cccc}
u_{11} y_{11} & u_{12} y_{12} & \ldots & u_{1 s} y_{1 s} \\
u_{21} y_{21} & u_{22} y_{22} & & u_{1 s} y_{2 s} \\
\vdots & & \ddots & \vdots \\
u_{n 1} y_{n 1} & u_{n 2} y_{n 2} & \ldots & u_{n s} y_{n s}
\end{array}\right]
$$

Langkah berikutnya adalah untuk setiap unit DMU dibentuk suatu virtual input (total input terbobot) dan suatu virtual output (total output terbobot). Virtual output adalah penjumlahan seluruh output-output yang telah terbobot. Virtual input adalah penjumlahan seluruh input-input yang telah terbobot. Untuk setiap unit DMU dibentuk suatu virtual input dan virtual output yang dapat dinyatakan sebagai berikut:

$$
\text { Virtual input } \mathrm{DMU}_{\mathrm{o}}=v_{o 1} x_{o 1}+v_{o 2} x_{o 2}+\ldots+v_{o m} x_{o m}=\sum_{i=1}^{m} v_{o i} x_{o i}
$$

dengan $\mathrm{v}_{\mathrm{oi}} \geq 0$

$$
\text { Virtual output } \mathrm{DMU}_{\mathrm{o}}=u_{o 1} y_{o 1}+u_{o 2} y_{o 2}+\ldots+u_{o s} y_{o s}=\sum_{r=1}^{s} u_{o r} y_{o r}
$$

dengan $\mathrm{u}_{\mathrm{or}} \geq 0$

Pada model Data Envelopment Analysis diperkenalkan suatu ukuran efisiensi relatif untuk masing-masing decision making unit (DMU) yang merupakan rasio/perbandingan antara virtual output dengan virtual input ${ }^{[3]}$, yaitu:

$$
\text { Efisiensi relatif }=\frac{\text { virtual output }}{\text { virtual input }}
$$


Rumus (3) apabila dimasukkan nilai virtual output (2) dan virtual input (1) pada $\mathrm{DMU}_{\mathrm{o}}$ adalah sebagai berikut:

$$
\text { Efisiensi relatif } \mathrm{DMU}_{\mathrm{o}}=\frac{u_{o 1} y_{o 1}+u_{o 2} y_{o 2}+\ldots+u_{o s} y_{o s}}{v_{o 1} x_{o 1}+v_{o 2} x_{o 2}+\ldots+v_{o m} x_{o m}}=\frac{\sum_{\mathrm{r}=1}^{\mathrm{s}} \mathrm{u}_{o r} \mathrm{y}_{o r}}{\sum_{\mathrm{i}=1}^{\mathrm{m}} \mathrm{v}_{\mathrm{oi}} \mathrm{x}_{\mathrm{oi}}}
$$

Persamaan (4) disebut juga permasalahan program pecahan (fractional programming) (FPo) atau juga disebut sebagai program nonlinear matematik. Kemudian untuk dapat mencari nilai efisiensi relatif dan nilai bobot input serta bobot output dari persamaan di atas maka harus menyelesaikan permasalahan program nonlinear matematik. Penyelesaian didapatkan dengan memaksimumkan nilai efisiensi relatif. Formulasi program nonlinear matematik dituliskan sebagai berikut:

(FPo) $\quad \max \theta_{o}=\frac{u_{o 1} y_{o 1}+u_{o 2} y_{o 2}+\ldots+u_{o s} y_{o s}}{v_{o 1} x_{o 1}+v_{o 2} x_{o 2}+\ldots+v_{o m} x_{o m}}$

$$
\max \theta_{o}=\frac{\sum_{r=1}^{s} u_{o r} y_{o r}}{\sum_{i=1}^{m} v_{o i} x_{o i}}
$$

Dengan kendala:

$$
\begin{aligned}
& \text { 1) } \frac{\sum_{j=1}^{n} \sum_{r=1}^{s} u_{j r} y_{j r}}{\sum_{j=1}^{n} \sum_{i=1}^{m} v_{j i} x_{j i}} \leq 1 \\
& \text { 2) } \mathrm{v}_{\mathrm{o} 1}, \mathrm{v}_{\mathrm{o} 2}, \ldots, \mathrm{v}_{\mathrm{om}} \geq 0 \\
& \text { 3) } \mathrm{u}_{\mathrm{o} 1}, \mathrm{u}_{\mathrm{o} 2}, \ldots, \mathrm{u}_{\mathrm{os}} \geq 0
\end{aligned}
$$

Keterangan:

$\theta_{o}$ adalah efisiensi relatif $\mathrm{DMU}_{\mathrm{o}}$.

Permasalahan program nonlinear di atas (Persamaan (5)) atau yang disebut juga program pecahan sangat sulit untuk ditemukan solusinya. Pada umumnya program pecahan tidak dapat diselesaikan perhitungannya. Agar dapat menyelesaikan program pecahan maka program pecahan tersebut perlu diubah kedalam bentuk program yang lebih sederhana yaitu bentuk program linear. Bentuk program linear didapatkan dengan menambahkan satu kendala baru yaitu:

$$
v_{o 1} x_{o 1}+v_{o 2} x_{o 2}+\ldots+v_{o m} x_{o m}=\sum_{i=1}^{m} v_{o i} x_{o i}=1
$$

Bentuk permasalahan program linear tersebut dapat ditulis sebagai berikut:

(LPo) $\max \theta_{o}=u_{o 1} y_{o 1}+u_{o 2} y_{o 2}+\ldots+u_{o s} y_{o s}$

$$
\max \theta_{o}=\sum_{r=1}^{s} u_{o r} y_{o r}
$$

Kendala:

$$
\begin{aligned}
& \text { 1) } v_{o 1} x_{o 1}+v_{o 2} x_{o 2}+\ldots+v_{o m} x_{o m}=\sum_{i=1}^{m} v_{o i} x_{o i}=1 \\
& \text { 2) } \sum_{j=1}^{n} \sum_{r=1}^{s} u_{j r} y_{j r}-\sum_{j=1}^{n} \sum_{i=1}^{m} v_{j i} x_{j i} \leq 0
\end{aligned}
$$


3) $\mathrm{v}_{\mathrm{o} 1}, \mathrm{v}_{\mathrm{o} 2}, \ldots, \mathrm{v}_{\mathrm{om}} \geq 0$

4) $\mathrm{u}_{\mathrm{o} 1}, \mathrm{u}_{\mathrm{o} 2}, \ldots, \mathrm{u}_{\mathrm{os}} \geq 0$

Permasalahan program linear (Persamaan (10)) disebut model Data Envelopment Analysis Constant Return To Scale (DEA CRS). Permasalahan DEA CRS dapat diselesaikan dengan metode simpleks pada program linear. Dari penyelesaian permasalahan DEA CRS akan didapatkan output yaitu $\theta_{o}{ }^{*}, \mathrm{u}_{\mathrm{or}}{ }^{*}$ dan $\mathrm{v}_{\mathrm{oi}}{ }^{*}$ dimana $\mathrm{u}_{\mathrm{or}}{ }^{*}$ dan $\mathrm{v}_{\mathrm{oi}}{ }^{*}$ bernilai lebih besar dari nol sesuai dengan kendala yang diberikan pada (13) dan (14).

\section{Data dan Analisis}

\subsection{Data}

Data yang digunakan adalah data sekunder yang diperoleh dari situs website resmi Bank Indonesia yaitu www.bi.go.id. BPR tersebut berjumlah 16 unit dan tersebar di seluruh kota Semarang, data diakses untuk keadaan bulan Maret 2009.

Untuk penghitungan efisiensi relatif variabel input yang digunakan adalah:

1) Modal $\left(\mathrm{x}_{1}\right)$ adalah modal disetor untuk operasional BPR. Variabel modal disetor ini mencerminkan kekuatan finansial bank, dengan satuan ukur ribuan rupiah.

2) Biaya bunga $\left(\mathrm{x}_{2}\right)$ adalah biaya yang dikeluarkan pihak BPR atas semua jenis simpanan yang ada pada bank tersebut, satuan ukurnya adalah ribuan rupiah.

3) Biaya operasional bank lainnya $\left(\mathrm{x}_{3}\right)$ adalah biaya yang digunakan pihak BPR untuk melakukan kegiatan operasionalnya dalam jangka waktu satu tahun, dengan satuan ukur ribuan rupiah. Biaya ini terdiri dari biaya adminstrasi umum, biaya personalia, biaya penurunan aktiva produktif, dan biaya lain-lain yang dikeluarkan oleh bank diluar ketiga biaya yang telah disebutkan.

Sedangkan variabel output yang digunakan adalah:

1) Pendapatan Kredit Pinjaman $\left(y_{1}\right)$ adalah semua pendapatan yang diperoleh BPR dari pemberian kredit dan simpanan di Bank Indonesia, dengan satuan ukur ribuan rupiah.

2) Pendapatan operasional lainnya $\left(\mathrm{y}_{2}\right)$ adalah pendapatan yang diperoleh pihak BPR dari operasional perbankan selain pendapatan bunga, seperti komisi, provisi, fee, dan lainnya, dengan satuan ukur ribuan rupiah.

\subsection{Analisis Data}

Data yang diperoleh selanjutnya dianalisis dengan menggunakan paket program WARWICK DEA versi 9. Diperoleh nilai bobot input dan bobot output yang direkap seperti dalam Tabel 1.

Berdasarkan Tabel 1 tersebut masih ada 10 BPR yang belum efisien. Jika besarnya nilai aktual sudah sama dengan nilai targetnya maka efisiensi untuk setiap input atau output sudah terjadi. Sebaliknya jika nilai antara aktual dengan target tidak sama maka efisiensi belum tercapai. BPR yang belum efisien dapat mencapai tingkat efisiensi yang optimal yaitu dengan nilai efisiensi $100 \%$ dengan cara mencapai target yang ditetapkan berdasarkan BPR rujukannya (BPR yang telah efisien). Dengan menggunakan paket program WARWICK DEA versi 9 diperoleh input dan output target yang dapat direkap seperti pada Tabel 2 dan Tabel 3.

Berdasarkan Tabel 2 terlihat bahwa nilai aktual untuk modal $\left(\mathrm{X}_{1}\right)$, Biaya Bunga $\left(\mathrm{X}_{2}\right)$ maupun Biaya Operasional $\left(\mathrm{X}_{3}\right)$ lebih tinggi dari nilai target yang disarankan. Perlu tindak lanjut untuk menekan biaya bunga maupun biaya operasional sehingga modal yang ada dapat dipergunakan secara optimal.

Berdasarkan Tabel 3 terlihat bahwa nilai target untuk Pendapatan Kredit Pinjaman $\left(\mathrm{Y}_{1}\right)$ sudah tercapai. Target untuk Pendapatan Operasional Lainnya $\left(\mathrm{Y}_{2}\right)$ dari beberapa BPR (No. 7, 8, 10, 11, 15 dan 16) belum tercapai. 
Tabel 1. Rekapitulasi Nilai Bobot Input, Bobot Output pada Masing-Masing BPR dan Nilai Efisiensi

\begin{tabular}{|c|c|c|c|c|c|c|c|}
\hline $\begin{array}{c}\text { NO } \\
\text { BPR }\end{array}$ & v1 & $\mathrm{v} 2$ & v3 & u1 & $\mathrm{u} 2$ & $\begin{array}{c}\text { NILAI } \\
\text { EFISIENSI }\end{array}$ & KETERANGAN \\
\hline 1 & 0 & $6.0924 \mathrm{E}-07$ & $2.66362 \mathrm{E}-07$ & 0 & $1.17895 \mathrm{E}-06$ & $77.10 \%$ & Tidak Efisien \\
\hline 2 & $1.15 \mathrm{E}-08$ & $2.40589 \mathrm{E}-06$ & $2.2023 \mathrm{E}-06$ & $1.26828 \mathrm{E}-06$ & $2.05943 \mathrm{E}-06$ & $77.72 \%$ & Tidak Efisien \\
\hline 3 & $1.6665 \mathrm{E}-07$ & $2.32729 \mathrm{E}-06$ & $7.9925 \mathrm{E}-07$ & $6.39274 \mathrm{E}-07$ & $3.11841 \mathrm{E}-06$ & $100 \%$ & Efisien \\
\hline 4 & 9.93E-08 & $5.16066 \mathrm{E}-07$ & $8.54829 \mathrm{E}-07$ & $7.5458 \mathrm{E}-07$ & 0 & $75.52 \%$ & Tidak Efisien \\
\hline 5 & 0 & $1.35519 \mathrm{E}-06$ & $1.49362 \mathrm{E}-06$ & $7.44971 \mathrm{E}-07$ & $2.51845 \mathrm{E}-06$ & $68.65 \%$ & Tidak Efisien \\
\hline 6 & 4.334E-08 & $1.5453 \mathrm{E}-05$ & 1.0747E-06 & $1.85666 \mathrm{E}-06$ & $8.15858 \mathrm{E}-06$ & $100 \%$ & Efisien \\
\hline 7 & $1.119 \mathrm{E}-07$ & $7.12486 \mathrm{E}-07$ & 0 & $4.39819 \mathrm{E}-07$ & 0 & $99.51 \%$ & Tidak Efisien \\
\hline 8 & $2.89625 \mathrm{E}-08$ & $1.80664 \mathrm{E}-06$ & $8.56792 \mathrm{E}-07$ & $9.09717 \mathrm{E}-07$ & 0 & $85.95 \%$ & Tidak Efisien \\
\hline 9 & $8.3325 \mathrm{E}-08$ & $1.30576 \mathrm{E}-07$ & $1.25137 \mathrm{E}-07$ & 6.46859E-08 & 5.83343E-07 & $100 \%$ & Efisien \\
\hline 10 & $4.66167 \mathrm{E}-08$ & $3.26794 \mathrm{E}-07$ & $1.9745 \mathrm{E}-07$ & $3.00139 \mathrm{E}-07$ & 0 & $74.41 \%$ & Tidak Efisien \\
\hline 11 & $1.98 \mathrm{E}-08$ & 0 & $3.14054 \mathrm{E}-06$ & $9.12711 \mathrm{E}-07$ & 0 & $86.42 \%$ & Tidak Efisien \\
\hline 12 & $8.3325 \mathrm{E}-08$ & $4.33406 \mathrm{E}-07$ & $3.89799 \mathrm{E}-07$ & $1.64918 \mathrm{E}-07$ & $1.12881 \mathrm{E}-06$ & $100 \%$ & Efisien \\
\hline 13 & $1.117 \mathrm{E}-08$ & $4.68102 \mathrm{E}-08$ & $6.56422 \mathrm{E}-07$ & $2.07142 \mathrm{E}-07$ & $3.78162 \mathrm{E}-07$ & $100 \%$ & Efisien \\
\hline 14 & $2.8475 \mathrm{E}-07$ & $3.25751 \mathrm{E}-07$ & $2.62534 \mathrm{E}-06$ & $8.06485 \mathrm{E}-07$ & $1.65817 \mathrm{E}-06$ & $100 \%$ & Efisien \\
\hline 15 & $8.565 \mathrm{E}-08$ & $6.00566 \mathrm{E}-07$ & $3.62815 \mathrm{E}-07$ & $5.51581 \mathrm{E}-07$ & 0 & $50.32 \%$ & Tidak Efisien \\
\hline 16 & $2.5875 \mathrm{E}-08$ & $1.11452 \mathrm{E}-07$ & $1.95258 \mathrm{E}-07$ & $1.76224 \mathrm{E}-07$ & 0 & $99.79 \%$ & Tidak Efisien \\
\hline
\end{tabular}

Tabel 2. Nilai Aktual dan Target dari Variabel Input (dalam ribuan) BPR yang Belum Efisien

\begin{tabular}{|c|r|r|r|r|r|r|}
\hline \multirow{2}{*}{$\begin{array}{c}\text { NO } \\
\text { BPR }\end{array}$} & \multicolumn{2}{|c|}{$\mathbf{X}_{\mathbf{1}}$} & \multicolumn{2}{|c|}{$\mathbf{X}_{\mathbf{2}}$} & \multicolumn{2}{c|}{$\mathbf{X}_{\mathbf{3}}$} \\
\hline & \multicolumn{1}{|c|}{ Aktual } & \multicolumn{1}{c|}{ Target } & \multicolumn{1}{c|}{ Aktual } & \multicolumn{1}{c|}{ Target } & \multicolumn{1}{c|}{ Aktual } & \multicolumn{1}{c|}{ Target } \\
\hline $\mathbf{1}$ & $15,000,000$ & $5,714,341.4$ & 957,586 & 738,269 & $1,564,034$ & $1,205,821.5$ \\
\hline $\mathbf{2}$ & $3,000,000$ & $2,331,487.5$ & 155,452 & $120,811.5$ & 268,583 & $208,732.6$ \\
\hline $\mathbf{4}$ & $3,000,000$ & $2,265,574.5$ & 543,923 & 410,766 & 492,964 & $372,282.2$ \\
\hline $\mathbf{5}$ & $4,000,000$ & $2,316,912.3$ & 312,577 & $214,924.5$ & 385,908 & $265,346.1$ \\
\hline $\mathbf{7}$ & $5,000,000$ & $4,975,550.3$ & 618,258 & $615,234.8$ & $1,548,423$ & $1,246,494.5$ \\
\hline $\mathbf{8}$ & $8,000,000$ & $6,876,186.4$ & 160,242 & $137,731.7$ & 558,829 & $480,326.5$ \\
\hline $\mathbf{1 0}$ & $6,000,000$ & $4,464,820$ & $1,207,183$ & $898,309.1$ & $1,650,037$ & $1,227,853$ \\
\hline $\mathbf{1 1}$ & $3,500,000$ & $3,024,698.8$ & 521,133 & $378,207.5$ & 296,350 & $256,105.6$ \\
\hline $\mathbf{1 5}$ & $4,000,000$ & $2,012,878.3$ & 560,638 & 282,124 & 883,645 & $444,667.5$ \\
\hline $\mathbf{1 6}$ & $8,000,000$ & $7,983,540.9$ & $2,760,818$ & $2,755,137.9$ & $2,485,426$ & $2,480,312.5$ \\
\hline
\end{tabular}

Tabel 3. Nilai Aktual dan Target dari Variabel Output (dalam ribuan) BPR yang Belum Efisien

\begin{tabular}{|c|c|c|c|c|}
\hline \multirow[t]{2}{*}{ NO BPR } & \multicolumn{2}{|c|}{$Y_{1}$} & \multicolumn{2}{|c|}{$\mathbf{Y}_{2}$} \\
\hline & Aktual & Target & Aktual & Target \\
\hline 1 & $2,430,917$ & $2,484,469.9$ & 653,969 & 653,969 \\
\hline 2 & 463,619 & $463,619.0$ & 91,870 & $91,870.0$ \\
\hline 4 & $1,000,821$ & $1,000,821$ & 811,610 & $215,623.3$ \\
\hline 5 & 648,616 & 648,616 & 148,359 & 148,359 \\
\hline 7 & $2,262,521$ & $2,262,521$ & 193,611 & $510,663.6$ \\
\hline 8 & 944,799 & 944,799 & 121,124 & $131,123.6$ \\
\hline 10 & $2,479,181$ & $2,479,181$ & 501,775 & $619,518.7$ \\
\hline 11 & 946,850 & 946,850 & 53,178 & $61,248.2$ \\
\hline 15 & 912,286 & 912,286 & 179,430 & $237,744.6$ \\
\hline 16 & $5,662,672$ & $5,662,672$ & 867,868 & $1,125,569.3$ \\
\hline
\end{tabular}




\section{Kesimpulan}

Dari pembahasan yang telah diuraikan pada bab sebelumnya maka dapat diambil kesimpulan sebagai berikut:

1. Metode Data Envelopment Analysis dapat memberikan gambaran berdasarkan nilai efisiensi relatif suatu unit BPR dibandingkan dengan BPR lainnya sehingga pihak BPR dapat menata kembali kondisi operasional BPR agar dapat mencapai kinerja yang lebih baik lagi.

2. Metode Data Envelopment Analysis dapat memberikan gambaran target-target untuk perbaikan sehingga pihak manajemen dapat mengambil tindakan untuk mencapai efisiensi yang optimal (100\%).

\section{DAFTAR PUSTAKA}

1. Bank Indonesia, Laporan Keuangan Publikasi Bank BPR Konvensional, 2009, URL: http://www.bi.go.id.

2. Coelli, T.J., Rao, P., O’Donnell, C.J. and Battese, G.E., An Introduction To Efficiency and Productivity Analysis, Springer Science Business Media, 2005.

3. Cooper, W.W., Seiford, L.M. and Tone, K, A Comprehensive Text with Models, Applications, References and DEA-Solver Software, Springer Science Business Media, New York, 2007.

4. Hussein, K.A., Efficiency In Islamic Banking, Islamic Research and Training Institute, Turkey, 2007.

5. Ray, S.C., Data Envelopment Analysis Theory and Techniques for Economics and Operations Research, Cambridge University Press, New York, 2004.

6. Talluri, S., Data Envelopment Analysis: Models and Extensions, Pennsylvania State University, 2000. 